\title{
Reductive Elimination of Alkylamines from Low-Valent, Alkylpalladium(II) Amido Complexes
}

\author{
Patrick S. Hanley, ${ }^{\ddagger}$ Seth L. Marquard, ${ }^{\ddagger}$ Thomas R. Cundari, ${ }^{\dagger}$ and John F. Hartwig ${ }^{*} \neq, \S$ \\ ${ }^{\ddagger}$ Department of Chemistry, University of Illinois at Urbana-Champaign, Urbana, Illinois 61801, United States \\ ${ }^{\S}$ Department of Chemistry, University of California, Berkeley, California 94720, United States \\ ${ }^{\dagger}$ Department of Chemistry and Center for Advanced Scientific Computing and Modeling, University of North Texas, Denton, Texas \\ 76203, United States
}

Supporting Information

ABSTRACT: A series of three-coordinate norbornylpalladium amido complexes ligated by bulky $\mathrm{N}$-heterocyclic carbene (NHC) ligands were prepared that undergo reductive eliminations to form the alkyl-nitrogen bond of alkylamine products. The rates of reductive elimination reveal that complexes containing more-electron-donating amido groups react faster than those with less-electrondonating amido groups, and complexes containing moresterically bulky amido groups undergo reductive elimination more slowly than complexes containing lesssterically bulky amido groups. Complexes ligated by more-electron-donating ancillary NHC ligands undergo reductive elimination faster than complexes ligated by lesselectron-donating NHC ligands. In contrast to the reductive elimination of benzylamines from bisphosphine-ligated palladium amides, these reactions occur with retention of configuration at the alkyl group, indicating that these reductive eliminations proceed by a concerted pathway. The experimentally determined free energy barrier of $26 \mathrm{kcal} / \mathrm{mol}$ is close to the computed free energy barrier of $23.9 \mathrm{kcal} / \mathrm{mol}(363 \mathrm{~K})$ for a concerted reductive elimination from the isolated, three-coordinate NHC-ligated palladium anilido complex.

$\mathrm{R}$ eductive elimination is a fundamental organometallic transformation that is proposed to be the product-forming step in numerous catalytic cycles. ${ }^{1}$ Although $\mathrm{C}-\mathrm{N}$ bondforming reductive eliminations of arylamines from a variety of transition metal amido complexes are known, reductive elimination of an alkylamine from an isolated metal amido complex has only been observed in a few cases. Hillhouse has reported the intramolecular reductive elimination of an indoline from a nickel amide in the presence of an oxidant, ${ }^{2,3}$ and Goldberg has reported the reductive elimination of a sulfonamide from a methylplatinum(IV) sulfonamido complex by dissociation of the sulfonamide ligand. ${ }^{4}$ However, the direct, thermal reductive elimination of an alkylamine from an isolated, low-valent metal amido complex is not well documented. ${ }^{5}$

Several palladium-catalyzed reactions have been proposed to occur by reductive elimination from a palladium amido complex to form new $\mathrm{C}\left(\mathrm{sp}^{3}\right)-\mathrm{N}$ bonds. Several $\mathrm{C}\left(\mathrm{sp}^{3}\right)-\mathrm{H}$ amidation reactions with added oxidants have been reported. $^{6-9}$ These reactions presumably generate a high-valent
Pd intermediate that would be prone to $\mathrm{C}-\mathrm{N}$ bond-forming reductive elimination. In addition, several Pd-catalyzed reactions that form $\mathrm{C}\left(\mathrm{sp}^{3}\right)-\mathrm{N}$ bonds without external oxidant have been reported, including the Pd-catalyzed formation of norbornylindoline $\mathrm{1}^{10,11}$ and an intermolecular amination of $\mathrm{C}-$ $\mathrm{H}$ bonds. ${ }^{12}$ The species that undergoes the reductive elimination step has not been observed directly in these systems.

Recently, our group reported examples of $\mathrm{C}\left(\mathrm{sp}^{3}\right)-\mathrm{N}$ and $\mathrm{C}\left(\mathrm{sp}^{3}\right)-\mathrm{O}$ bond-forming reductive elimination of benzylamines and benzyl ethers from isolated benzylpalladium(II) amido and phenoxide complexes ligated by a chelating phosphine ligand, as shown in eq $1 .^{13,14}$ Kinetic and stereochemical studies

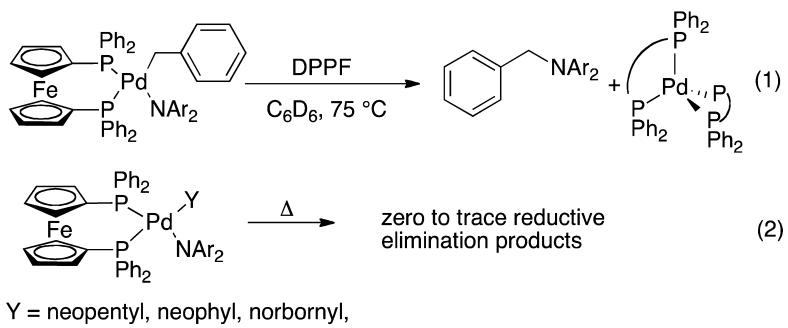

implied that these reactions proceed by a stepwise pathway that involves dissociation of the diarylamido ligand, followed by nucleophilic attack of the amide onto a proposed $\eta^{3}$ benzylpalladium intermediate. However, reductive elimination to form an alkyl-nitrogen bond from an isolated Pd complex has not been reported, despite significant effort. ${ }^{15,16}$ Thermolysis of 1,1'-Bis(diphenylphosphino)ferrocene (DPPF) ligated alkylpalladium amido complexes that are analogues of the benzylpalladium amido complexes did not generate products from reductive elimination (eq 2). ${ }^{17}$

Here, we report a series of isolated and fully characterized three-coordinate Pd-alkylamido complexes ligated by bulky, monodentate $\mathrm{N}$-heterocyclic carbene (NHC) ligands that undergo direct thermal reductive eliminations of $\mathrm{N}$-alkylamines. The stereochemical outcome of the norbornylamine products from the reductive elimination step implies that these reactions occur by a concerted reductive elimination.

Received: August 1, 2012

Published: August 30, 2012 
Synthesis of the Pd-amido complexes in this study is summarized in Scheme 1. To isolate Pd-alkylamido complexes

Scheme 1. Preparation of SIPr-Ligated Norbornylpalladium Amido Complexes 2a-f

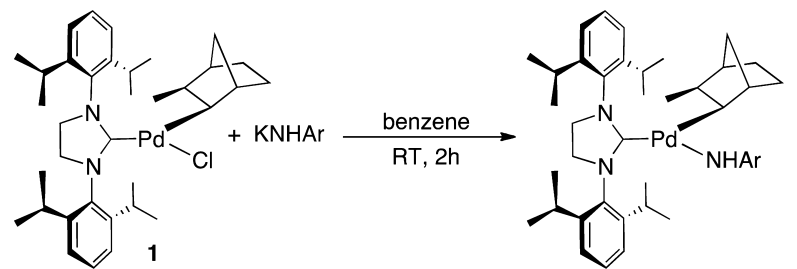

2a, $80 \% ; \mathrm{Ar}=4-\mathrm{CH}_{3} \mathrm{C}_{6} \mathrm{H}_{4} \quad$ 2d, $75 \% ; \mathrm{Ar}=2-\mathrm{CH}_{3} \mathrm{C}_{6} \mathrm{H}_{4}$ 2b, 51\%; $\mathrm{Ar}=4-\mathrm{OCH}_{3} \mathrm{C}_{6} \mathrm{H}_{4}$ 2e, $72 \% ; \mathrm{Ar}=2,6-\left(\mathrm{CH}_{3}\right)_{2} \mathrm{C}_{6} \mathrm{H}_{3}$ 2c, $55 \% ; A r=3-\mathrm{CF}_{3} \mathrm{C}_{6} \mathrm{H}_{4} \quad$ 2f, $72 \% ; A r=2,4-\left(\mathrm{CH}_{3}\right)_{2} \mathrm{C}_{6} \mathrm{H}_{3}$

that are stable to $\beta$-hydrogen elimination, norbornylpalladium complexes were prepared. The $\beta$-hydrogen atoms in the norbornyl ligand are known to be resistant to $\beta$-hydrogen elimination. ${ }^{18}$ The SIPr-ligated palladium chloride complex 1 was prepared by ligand substitution of $(\mathrm{COD}) \mathrm{Pd}\left(2-\mathrm{CH}_{3}-\right.$ norbornyl)Cl ${ }^{18}$ with 1,3-bis(2,6-diisopropylphenyl)imidazolidin-2-ylidene (SIPr) in THF at room temperature. $\mathrm{X}$-ray crystallographic analysis showed that complex 1 exists as a stable, three-coordinate chloride complex in the solid state. Palladium anilido complexes $\mathbf{2 a - f}$ were synthesized in good yields from the reaction of chloride 1 with KNHAr salts in benzene over $2-4 \mathrm{~h}$ at room temperature. In solution, the SIPr ligand of each $\mathrm{Pd}$-amido complex rotates freely about the $\mathrm{Pd}-\mathrm{C}$ bond, as evidenced by two doublet resonances and one triplet resonance observed in the ${ }^{1} \mathrm{H}$ NMR spectrum between $\delta 7.32$ and 7.03, each integrating to two hydrogen atoms.

The solid-state structure of $\mathbf{2} \mathbf{b}$ was determined by singlecrystal X-ray diffraction, and an ORTEP drawing is shown in Figure 1. Complex $\mathbf{2 b}$ is a stable, three-coordinate palladium

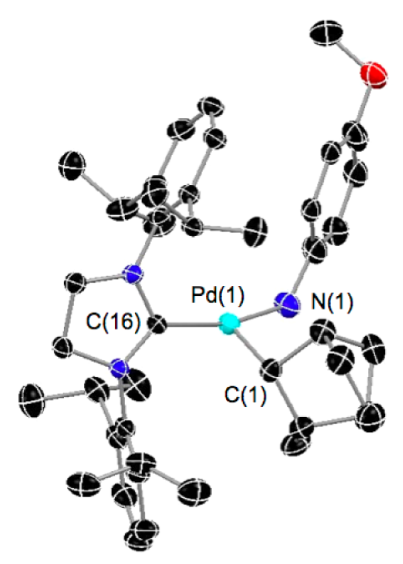

Figure 1. ORTEP drawing of $\mathbf{2} \mathbf{b}$ with $35 \%$ probability ellipsoids. Hydrogen atoms are omitted for clarity. Selected bond angles (degrees) and lengths $(\AA): \mathrm{C}(16)-\mathrm{Pd}(1)-\mathrm{N}(1), 161.28(12)$; $\mathrm{C}(16)-\mathrm{Pd}(1)-\mathrm{C}(1), 89.35(12) ; \mathrm{N}(1)-\mathrm{Pd}(1)-\mathrm{C}(1), \quad 109.15(13)$; Pd-C(16), 1.974(3); Pd-N, 2.037(3); Pd-C(1), 2.044(3).

amide that possesses a distorted $\mathrm{T}$-shaped geometry and does not form an N-bridged dimeric Pd-amido structure, which is common among metal anilido complexes. ${ }^{19-21}$ The carbene ligand is oriented cis to the open coordination site, and the 2methylnorbornyl ligand has the syn-exo configuration. Previously prepared three-coordinate arylpalladium diarylamido complexes ligated by tri-tert-butylphosphine possessed C-Pd$\mathrm{N}$ angles between 88.75 and $93.46^{\circ}$ and $\mathrm{P}-\mathrm{Pd}-\mathrm{N}$ angles between 166.00 and $170.66^{\circ} .^{22}$ Complex $2 \mathrm{~b}$ is more distorted from a true $\mathrm{T}$-shaped geometry than these previous complexes. The $\mathrm{C}$ (norbornyl) $-\mathrm{Pd}-\mathrm{N}$ angle is $109.15^{\circ}$, and the $\mathrm{C}$ (NHC) $-\mathrm{Pd}-\mathrm{C}$ (norbornyl) angle is $161.28^{\circ}$. The $\mathrm{Pd}-\mathrm{N}$ distance is $\sim 0.041 \AA$ shorter and the $\mathrm{Pd}-\mathrm{C}($ alkyl) distance is $\sim 0.057 \AA$ longer than those of $\left(\mathrm{P}(t-\mathrm{Bu})_{3}\right) \mathrm{Pd}(\mathrm{Ar}) \mathrm{NAr}^{\prime}{ }_{2}$ complexes (2.078 and $1.987 \AA$ ).

Warming of the SIPr-ligated Pd-norbornyl complexes $\mathbf{2 a - f}$ resulted in the reductive elimination of norbornylamines in good yields. The yields and rate constants for these reactions are shown in Table 1. The decomposition of Pd-amide $2 \mathbf{a}$ at 90

Table 1. Reductive Elimination of Norbornylamines from Pd-Amides $2 \mathrm{a}-\mathrm{f}$

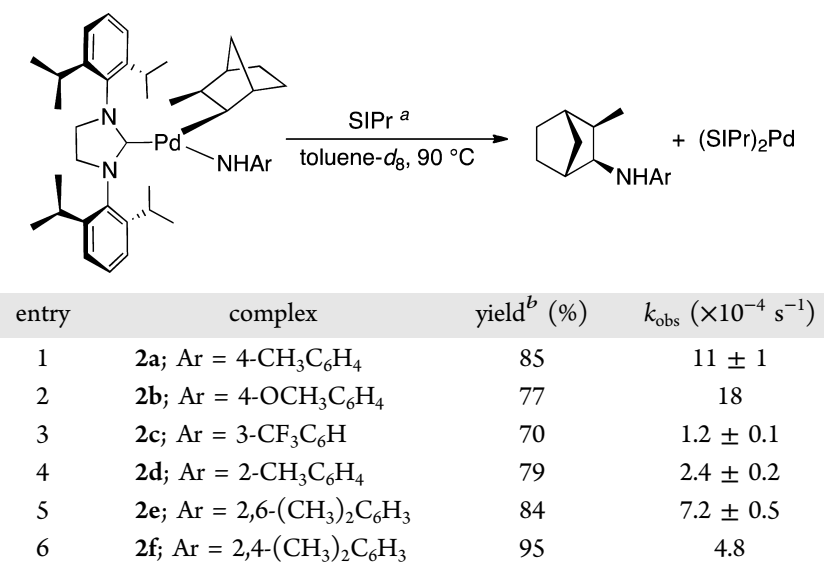

${ }^{a}$ Reactions were conducted in NMR tubes with $0.013 \mathrm{mmol}$ of Pdamide, $0.013 \mathrm{mmol}$ of SIPr, and $0.013 \mathrm{mmol}$ of trimethoxybenzene (TMB) in $0.4 \mathrm{~mL}$ of toluene- $d_{8}$ at $90{ }^{\circ} \mathrm{C}$. ${ }^{b}$ Yields determined by comparison of the integrated aryl reasonances of norbornylamine and TMB standard.

${ }^{\circ} \mathrm{C}$ formed 3-methyl-2-(4-methylanilino)norbornane product in $85 \%$ yield. The reductive elimination of $2 \mathrm{a}$ was conducted in both THF and toluene. The reaction was slightly faster in THF$d_{8}$ than in toluene- $d_{8}$ at $50{ }^{\circ} \mathrm{C}$, but by less than a factor of 2 . In the presence of 1 equiv of SIPr, the reaction generated $(\mathrm{SIPr})_{2} \mathrm{Pd}^{0}$ as the metal product in $89 \%$ yield.

The decay of the Pd-amides was monitored by ${ }^{1} \mathrm{H}$ NMR spectroscopy over time in the presence of 1 equiv of the NHC. The decay curves fit well to a first-order exponential from which the rate constants for reductive elimination were determined. The reductive elimination was found to be zeroorder in the concentration of added NHC. ${ }^{23}$

The data in Table 1 reveal the electronic and steric effects of the anilido ligand on the rate of reductive elimination: complexes containing more-electron-donating anilido ligands reacted faster than complexes containing less electron-donating anilide ligands. Complex $\mathbf{2} \mathbf{b}$, containing the most-electrondonating $p$-anisylamido ligand, reacted approximately 2 times faster than complex $\mathbf{2 a}$, containing the $p$-tolylamido ligand, and an order of magnitude faster than complex $2 c$, containing the less-electron-donating $m$-trifluoromethylamido ligand. The magnitude of the observed electronic effect on the rate of reductive elimination of alkylamines is similar to that observed on the reductive elimination of benzylamines ${ }^{13}$ and $N$ methyldiarylamines ${ }^{24}$ from isolated benzyl- and arylpalladium amido complexes. 
Complexes ligated by more-hindered anilido ligands reacted more slowly than complexes containing less-sterically hindered anilido ligands; however, the overall steric effect imparted by the anilido ligand on the rate of reductive elimination was small. The reductive elimination of complex $\mathbf{2 d}$, containing an $o$-tolyl substituent, was almost an order of magnitude slower than that of complex 2a, containing a $p$-tolyl group, but the reductive eliminations of complexes $2 \mathbf{e}$ and $\mathbf{2 f}$, containing 2,6- and 2,4dimethylanilido ligands, respectively, were faster than that of complex $\mathbf{2 d}$ and slower than that of complex $\mathbf{2 a}$. We propose that compensating steric and electronic effects of the substituents of the anilido ligand of $2 \mathrm{e}$ and $\mathbf{2 f}$ result in intermediate rate constants for the reductive elimination of the corresponding $N$-arylnorbornylamines.

To examine the effects of the ancillary NHC ligand on the rate of reductive elimination, we prepared a norbornylamido complex (4) ligated by the unsaturated $\mathrm{NHC}$, 1,3-bis(2,6diisopropylphenyl)imidazol-2-ylidene (IPr). Like that of $\mathbf{1}$, the synthesis of the chloride complex 3 for conversion to the anilide was accomplished by the reaction of 1 equiv of IPr with (COD) $\mathrm{Pd}\left(2-\mathrm{CH}_{3}\right.$-norbornyl) $\mathrm{Cl}$ in THF. X-ray crystallography showed that 3 exists as a dimeric Pd complex, with the two Pd centers bridging through the chloride ligands. In solution, two sets of resonances in the ${ }^{1} \mathrm{H}$ NMR spectra suggest that 3 exists as a mixture of cis and trans diastereomers at room temperature. At $90{ }^{\circ} \mathrm{C}$, a single set of resonances is observed that likely indicates rapid interconversion between the cis and trans diastereomers. Signer molecular weight analysis in benzene confirmed that the 3 adopts a dimeric structure at room temperature.

IPr-ligated complex 4 was isolated in $41 \%$ yield from the reaction of 3 with 1 equiv of $\mathrm{KNH}\left(4-\mathrm{CH}_{3} \mathrm{C}_{6} \mathrm{H}_{5}\right)$ in benzene (eq 3). Solid-state structural analysis confirmed that the IPr-

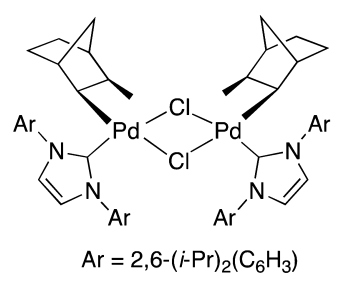

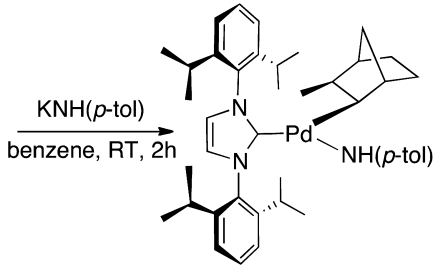

ligated norbornylamido complex is a stable three-coordinate monomer. Pd-amide 3 crystallized as two distinct molecules within the unit cell, both of which are less distorted from a true T-shape than the SIPr-ligated Pd-amide 2a. Complex 4 contains $\mathrm{C}(\mathrm{NHC})-\mathrm{Pd}-\mathrm{N}$ angles of 163.42 and $163.83^{\circ}$, $\mathrm{C}$ (norbornyl) $-\mathrm{Pd}-\mathrm{N}$ angles of 91.05 and $92.05^{\circ}$, and $\mathrm{C}-$ $\mathrm{Pd}-\mathrm{C}$ angles of 105.06 and $103.67^{\circ}$.

The preparation of analogous norbornylpalladium amido complexes ligated by 1,3-bis(2,4,6-trimethylphenyl)imidazol-2ylidene (IMes) did not lead to an isolable amido complex. The reaction of (IMes) $\mathrm{Pd}\left(2-\mathrm{CH}_{3}\right.$-norbornyl) $\mathrm{Cl}$ with $\mathrm{KNHAr}$ generated a mixture of products that we were unable to identify by ${ }^{1} \mathrm{H}$ NMR spectroscopy. The IMes ligand lacks the bulky isopropyl groups of SIPr and IPr that are likely necessary for the formation of stable, three-coordinate amido complexes.

Warming of IPr-ligated 4 in toluene at $90{ }^{\circ} \mathrm{C}$ in the presence of 1 equiv of $\mathrm{IPr}$ resulted in the reductive elimination of the norbornylamine product in $80 \%$ yield and $(\mathrm{IPr})_{2} \mathrm{Pd}^{0}$ in $92 \%$ yield (eq 4 ). The rate constant for the reductive elimination of $N$-norbornyltoluidine from $4,(5.7 \pm 0.1) \times 10^{-4} \mathrm{~s}^{-1}$, was 5

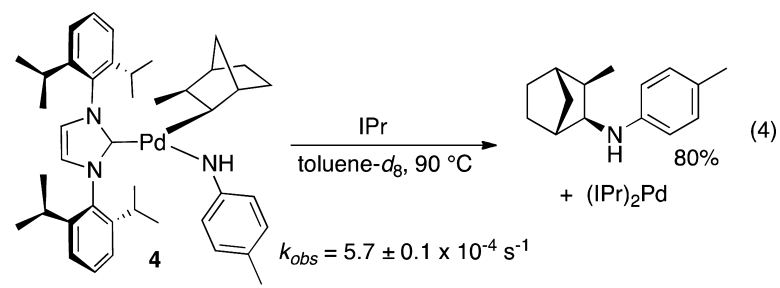

times smaller than the rate constant for the analogous reductive elimination from complex 2a. In contrast to reductive eliminations of benzylamines from four-coordinate benzylpalladium amido complexes, ${ }^{13}$ this result indicates that the reductive elimination of alkylamine is faster from complexes ligated by more-electron-donating ancillary NHC ligands.

The stable stereochemical configuration of the norbornyl ligand of the alkylpalladium amido complexes provides a means to assess the mechanism of the reductive elimination step. The reductive elimination of the norbornylamines could proceed by one of the three pathways depicted in Scheme 2. A concerted

\section{Scheme 2. Possible Mechanisms for the Reductive Elimination of Norbornylamines from (SIPr)Pd(2- $\left.\mathrm{CH}_{3} \mathrm{C}_{7} \mathrm{H}_{10}\right)$ NHAr Complexes}

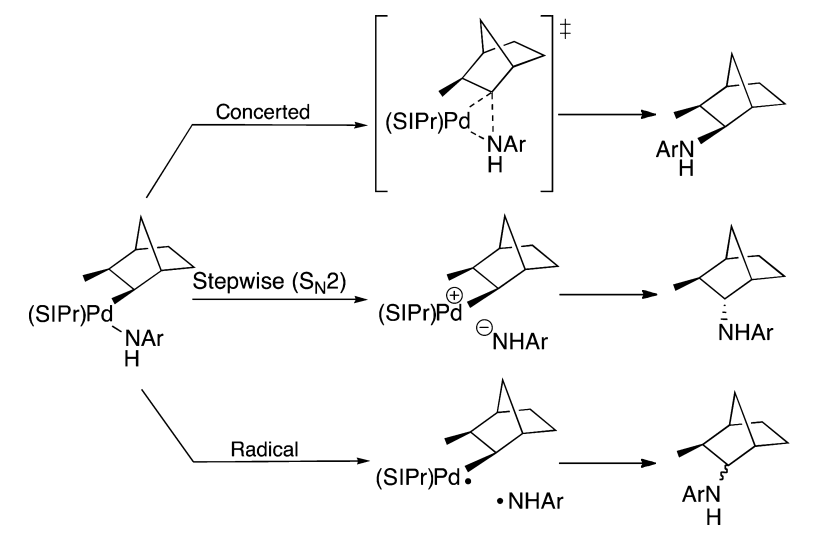

reductive elimination would lead to retention of the configuration of the norbornyl ligand in Pd-amide $\mathbf{2 a}$ and form the syn-exo-3-methyl-exo-2-(4-methylanilino)norbornane. A stepwise pathway involving dissociation of the amido ligand and backside nucleophilic attack onto the endo face of the norboryl ligand would result in inversion of the configuration, forming only the anti-exo-3-methyl-endo-2-(4-methylanilino)norbornane. Finally, a radical pathway would result in an erosion of the configuration and the formation of multiple isomers of the norbornylamine product.

To assess whether the stereochemical outcome of the reaction would be biased by the relative stabilities of the diastereomeric products, we computed the energies of the different stereoisomers. Energy minimizations by DFT indicate that the ground-state free energy of the syn-exo-3-methyl-exo-2anilinonorbornane isomer 8 is higher than that of either anti diastereomer 6 or 7 by about 1.4 and $1.7 \mathrm{kcal} / \mathrm{mol}$ (Figure 2). Thus, the product that would be formed by a concerted pathway is the least stable of the diastereomers.

Reductive eliminations from Pd-amides $\mathbf{2 a}-\mathbf{f}$ and $\mathbf{4}$ formed a single diastereomer. Independent preparation of syn- and antinorbornylamine isomers revealed that the syn-exo,exo diastereomer $\mathbf{8}$ is formed. ${ }^{25}$ Thus, this reaction occurs with retention of configuration at the palladium-bound carbon. This stereo- 


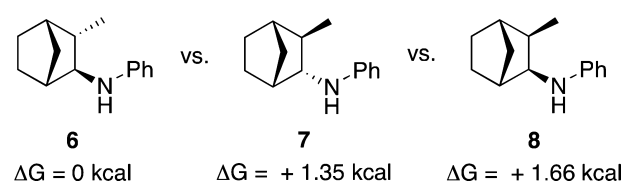

Figure 2. Computed relative ground-state free energies $(\Delta G)$ of three diastereomers of 3-methyl-2-anilinonorbornane.

chemical outcome implies that reductive elimination of the norbornylamine from the three-coordinate (SIPr)Pd(2$\mathrm{CH}_{3} \mathrm{C}_{7} \mathrm{H}_{10}$ ) NHAr complexes occurs by a concerted pathway.

Because a direct, concerted reductive elimination from an alkylpalladium amide has not been documented previously, we sought to determine if the barrier we measured for such a process is consistent with that computed for a concerted reductive elimination. Hybrid quantum mechanics/molecular mechanics (QM/MM) calculations were performed on a full chemical model of $\mathbf{2 f}$. The transition-state structure computed for a concerted reductive elimination is illustrated in Figure 3.

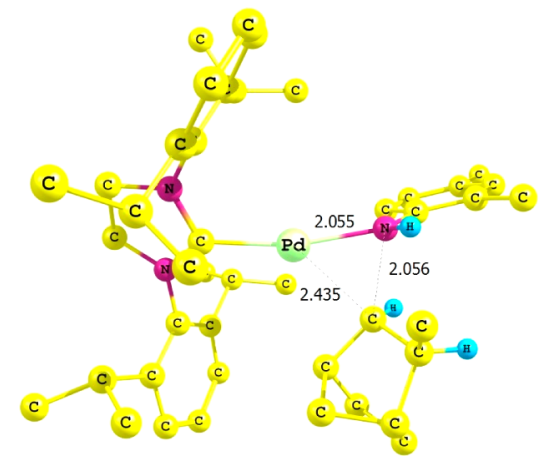

Figure 3. Computed transition-state structure of complex $2 \mathbf{f}$.

The QM/MM simulations indicated that this transition state lies $25.3\left(\Delta H^{\ddagger}\right)$ and $23.9\left(\Delta G^{\ddagger}\right) \mathrm{kcal} / \mathrm{mol}$ above the ground state of $2 \mathrm{f}$ at $363 \mathrm{~K}$. These barriers are similar to the $26 \mathrm{kcal} /$ mol barrier measured experimentally and are, therefore, consistent with the proposed concerted reductive elimination mechanism.

In conclusion, we report discrete, low-valent $\mathrm{Pd}$ complexes that undergo reductive elimination of alkylamines. The steric bulk of the SIPr and IPr ligands leads to the formation of stable three-coordinate palladium amido complexes, which undergo reductive elimination of alkylamine upon heating without an external oxidant to create a higher-valent intermediate. The stereochemical configuration of the norbornylamine products implies that these reductive eliminations occur by a concerted mechanism. This mechanism contrasts the stepwise mechanism for the reductive elimination of benzylamines from fourcoordinate DPPF-ligated benzylpalladium complexes. Future work will examine the reductive elimination of alkylamines from complexes ligated with a range of ancillary ligands and the development of new catalytic reactions involving this class of reductive elimination.

\section{ASSOCIATED CONTENT}

\section{S Supporting Information}

Experimental procedures, characterization of complexes and reductive elimination products, including CIF files, and computational details. This material is available free of charge via the Internet at http://pubs.acs.org.

\section{AUTHOR INFORMATION}

\section{Corresponding Author}

jhartwig@berkeley.edu

\section{Notes}

The authors declare no competing financial interest.

\section{ACKNOWLEDGMENTS}

We thank the NSF for financial support through the Center for Enabling New Technologies Through Catalysis (CENTC) and Danielle Gray for collection of X-ray data.

\section{REFERENCES}

(1) Hartwig, J. F. Organotransition metal chemistry: from bonding to catalysis; University Science Books: Sausalito, CA, 2010.

(2) Koo, K.; Hillhouse, G. L. Organometallics 1995, 14, 4421.

(3) Lin, B. L.; Clough, C. R.; Hillhouse, G. L. J. Am. Chem. Soc. 2002, 124, 2890.

(4) Pawlikowski, A. V.; Getty, A. D.; Goldberg, K. I. J. Am. Chem. Soc. 2007, 129, 10382.

(5) Hillhouse reported reductive elimination to form an indoline after $48 \mathrm{~h}$. Because these reactions occur rapidly in the presence of oxidant, it is unclear if this slow reaction is a purely unimolecular, thermal process or is catalyzed by a low concentration of oxidant.

(6) Iglesias, A.; Alvarez, R.; de Lera, A. R.; Muniz, K. Angew. Chem., Int. Ed. 2012, 51, 2225.

(7) Neumann, J. J.; Rakshit, S.; Droge, T.; Glorius, F. Angew. Chem., Int. Ed. 2009, 48, 6892.

(8) Mei, T. S.; Wang, X. S.; Yu, J. Q. J. Am. Chem. Soc. 2009, 131, 10806.

(9) Brice, J. L.; Harang, J. E.; Timokhin, V. I.; Anastasi, N. R.; Stahl, S. S. J. Am. Chem. Soc. 2005, 127, 2868.

(10) Lautens, M.; Paquin, J. F.; Piguel, S.; Dahlmann, M. J. Org. Chem. 2001, 66, 8127.

(11) Catellani, M.; Del Rio, A. Russ. Chem. Bull. 1998, 47, 928.

(12) Pan, J.; Su, M. J.; Buchwald, S. L. Angew. Chem., Int. Ed. 2011, $50,8647$.

(13) Marquard, S. L.; Rosenfeld, D. C.; Hartwig, J. F. Angew. Chem., Int. Ed. 2010, 49, 793.

(14) Marquard, S. L.; Hartwig, J. F. Angew. Chem., Int. Ed. 2011, 50, 7119.

(15) Esposito, O.; Gois, P. M. P.; Lewis, A. K. D. K.; Caddick, S.; Cloke, F. G. N.; Hitchcock, P. B. Organometallics 2008, 27, 6411.

(16) Esposito, O.; Lewis, A. K. D. K.; Hitchcock, P. B.; Caddick, S.; Cloke, F. G. N. Chem. Commun. 2007, 1157.

(17) Marquard, S. L. Ph.D. Thesis, University of Illinois at UrbanaChampaign, 2011.

(18) Kang, M.; Sen, A. Organometallics 2004, 23, 5396.

(19) Villanueva, L. A.; Abboud, K. A.; Boncella, J. M. Organometallics 1994, 13, 3921.

(20) Driver, M. S.; Hartwig, J. F. J. Am. Chem. Soc. 1996, 118, 4206.

(21) Driver, M. S.; Hartwig, J. F. Organometallics 1997, 16, 5706.

(22) Yamashita, M.; Hartwig, J. F. J. Am. Chem. Soc. 2004, 126, 5344.

(23) The rate constant for the reaction of $2 \mathrm{a}$ at $90^{\circ} \mathrm{C}$ in the presence of excess (10 equiv) SIPr was $1.0 \times 10^{-3} \mathrm{~s}^{-1}$.

(24) Yamashita, M.; Vicario, J. V. C.; Hartwig, J. F. J. Am. Chem. Soc. 2003, 125, 16347.

(25) Detailed procedures for the synthesis of the syn-exo,exonorbornylamine products from the reductive eliminations in this report are described in the Supporting Information. 